\title{
(o corpo na caixa): o gato \\ [ou: da condição de ver contemporânea, do visível e da cegueira]
}

Elisa de Magalhães*

RESUMO: O presente artigo aborda o ver num campo ampliado - um ver que não privilegia a visão como seu principal sentido, um ver cego que depende do não visível -, fundamentado no pensamento sobre o ver, sobre arte como événement e arte como experimentação de Jacques Derrida e Jean-François Lyotard. A autora discute a cegueira, o ver tátil e a visibilidade do som como alteridades do ver visível.

PALAVRAS-CHAVE: ver, cegueira, labirinto, corpo, evento.

ABSTRACT: This text presents the regard in the expanded field - a regard that doesn't privilege the seeing as the main sense, a blind regard that depends on the non-visible, grounded in Jacques Derrida and Jean-François Lyotard concept of art as an event and art as experimentation. The author discusses tactile regard and sound visibility as alterities of a visible regard.

KEY-WORDS: regard, blindness, labyrinth, body, event.

*Elisa de Magalhães é Professora Adjunta da Escola de Belas Artes/ UFRJ. Realizou pós-doutorado no Programa de Pós-graduação em Estudos Contemporâneos das Artes/UFF. 


\section{FEDRO}

- O que ela disse?

SÓCRATES

- Disse alguma coisa para si mesma.

ERIXÍMACO

- Ela disse: Como estou bem!

FEDRO

- Esse feixezinho de membros e véus se agita...

ERIXÍMACO

- Então, menina, vamos abrir os olhos. Como te sentes agora?

ATHIKTÊ

- Não sinto nada. Não estou morta. E contudo, não estou viva!

SÓCRATES

- De onde voltas?

ATHIKTÊ

- Asilo, asilo, ó meu asilo, Turbilhão! - Eu estava em ti, ó movimento, e fora de todas as coisas... (VALÉRY, 1996, p. 67/68)

Estes são os diálogos finais de A Alma e a Dança de Paul Valéry. Eles introduzem o assunto tratado aqui: o VER. Como o próprio trecho escolhido já anuncia, é um ver que está num campo mais ampliado, na medida em que prescinde da visão, ou melhor, que pode prescindir do que se convencionou ser o principal sentido do ver. É um ver cego, embora tátil, audível e também visível, e capaz de ver o que não há, a invisibilidade, ou um ver que entende que a invisibilidade é condição para o visível.

No mundo contemporâneo, dominado por imagens, até a palavra não só perde lugar, como não dá conta da imagem, do poder da imagem. A sujeição, a individualização e a fragmentação 
dos corpos, como forma de exercício de poder, ao longo da história da civilização, gerou uma espécie de voyeurismo moderno nas fábricas, nas escolas, nas prisões, o qual se desdobrou contemporaneamente, num controle de tal maneira eficaz que o ver, ou melhor, a visão ainda que presente é secundária, pois é um ver de outra ordem, porque a imagem tem valor por si própria, antes da fala ou da palavra. Em Filosofia da caixa preta - Ensaios para uma futura filosofia da fotografia, Vilém Flusser fala da característica magicizante da imagem técnica contemporânea:

A nova magia não precede, mas sucede à consciência histórica, conceitual, desmagicizante. A nova magia não visa modificar o mundo lá fora, como o faz a pré-história, mas os nossos conceitos em relação ao mundo. É magia de segunda ordem: feitiço abstrato. (...) a magia atual ritualiza outro tipo de modelo: programas. (FLUSSER, 2011, p. 32/33)

O filósofo chama atenção para esse comportamento mágico programado das imagens técnicas, um ritual cuja função é programar os receptores das imagens: as imagens técnicas têm por função emancipar a sociedade da necessidade de pensar conceitualmente.

\section{ATHIKTÊ}

- Não sinto nada. Não estou morta. E contudo, não estou viva! (VALÉRY, 1996, p. 68)

Quando Athiktê abriu os olhos e não sentiu nada, não estava morta, nem viva. Ela via, quando estava de olhos fechados. Nesse diálogo, na sequência, Sócrates pergunta "De onde voltas?" Era no asilo de seus olhos fechados que ela experimentava o turbilhão de imagens.

O interesse, aqui, é na cegueira como alteridade do ver, ou nas 'cegueiras' como alteridades dos 'veres', ou seja, ver no limite da visibilidade. Falar em limite é pensar visibilidade num campo expandido, isto é, visibilidade que pode estar no tato, no olfato, na audição ou em outros sentidos. Daí os 'veres', daí as 'cegueiras'. Deve-se levar em conta uma sinestesia e uma cinestesia permanentes e inerentes ao sensível.

Experiências que levaram em conta a percepção por mais de um sentido, aconteceram, entre outros movimentos, no Futurismo, na tentativa de traduzir em imagem a velocidade, o movimento. O fotodinamismo, pesquisa dos irmãos Bragaglia, continha certo transcendentalismo 
tecnológico. Na tentativa de captura do movimento (afinados com as perspectivas futuristas), esses cientistas queriam ir além do que as pesquisas de Eadweard Muybridge e ÉtienneJules Marey tinham conseguido com a cronofotografia - segundo eles, um processo analítico de conhecimento da realidade, conseguido graças à decomposição do movimento em dados constitutivos: uma imagem que continha poses que representavam etapas do movimento. Para eles era preciso representar todo o gesto, a dinâmica do movimento, de modo a capturar sua essência, e não vários instantâneos do movimento. Como eles próprios escreveram "visões proporcionadas, na força das imagens, no próprio tempo de sua vida, e, mais ainda, na velocidade com a qual viveram no espaço e em nós" (FABRIS, 2010, p. 61). Como se a imagem fotodinâmica pudesse revelar o não visível do gesto, ou melhor, como se a fotodinâmica pudesse revelar o que está sob o gesto. Nas palavras dos Bragaglia " emoção sensorial, cerebral e psíquica que experimentamos no momento em que um gesto deixava atrás de si seu soberbíssimo rastro irruente" (FABRIS, 2010, p. 62). Em verdade, a proposta dos irmãos era encontrar no fotodinamismo uma dimensão estética inerente a ele, que pudesse fazer ver a realidade interior das coisas, a atmosfera que envolve tudo, a carga emocional do gesto, certa psicologia das coisas. Como se perseguissem uma metafísica do movimento, isto é, o fotodinamismo não mais como um fenômeno ótico, mas fenomenológico. Em sua atitude eles tentavam fazer do fotodinamismo uma espécie de arte completa.

(...) Queremos traduzir o que não se vê na superfície: queremos lembrar a mais viva sensação da expressão profunda de uma realidade e procuramos, de fato, a movimentista porque é rica de magníficas, secretas profundidades e de múltiplas fontes emotivas que a tornam indizível e inapreensível. (FABRIS, 2010, p. 75)

A mesma tentativa de uma espécie de sinergia através da luz foi feita pelo escritor e dramaturgo August Strindberg, nas suas fotografias psicológicas, o "retrato verdadeiro", ou o "retrato psicológico". Para isso, escolheu uma câmera sem lentes (na época já existiam as máquinas mecânicas com sistemas de lentes), como as pinholes que, segundo ele, por não terem lente eliminavam esse obstáculo entre o filme e o fotografado, tornando possível a captura da essência do retratado. Além disso, o tempo de exposição para a impregnação da imagem no filme, numa câmera como essa, era muito maior, levava cerca de 1 a 2 minutos. Para preencher esse tempo, o dramaturgo fotógrafo inventava pequenas histórias que suscitassem no 
fotografado vários sentimentos diferentes, como alegria, tristeza, dor, etc., de modo que durante o ato fotográfico, pudessem ser captadas luz e matéria num fluidum. O que Strindberg perseguia era que a foto fizesse ver o não visível, a alma, a essência.

Anterior a essas experiências é o conceito de obra de arte total (ou integral) de Wagner, o Gesamtkunstwerk. Em um de seus escritos, de 1849, delineia um quadro idealizado do que chama de "obra de arte integrada", na tragédia grega. Ele pensava no aspecto comunitário da tragédia, que era o de agregar o povo de Atenas, promovendo um elo espiritual, através da união de todas as artes. Para Wagner, uma comunitária obra de arte do futuro. Assim, a concepção original do ciclo do Anel dos Nibelungos, ópera concebida com a intenção de ser uma arte completa, está imbuída desta versão do ideal grego - a peça como um festival cênico, que unia todas as artes, não somente a música e a ópera, mas o canto, o teatro, as artes plásticas, cenografia, a música, e que acabou por culminar no projeto de Bayreuth¹. O compositor acreditava que as artes separadas perdiam o potencial comunitário e revolucionário, porque transformador; e que estariam fadadas ao fracasso e à obsolescência. Wagner acreditava no potencial estético do que ele chamava de drama musical.

A visibilidade e a cegueira tornam-se mais presentes como questões, através das formulações de dois físicos por volta do segundo quarto do século XX. Os conceitos filosóficos subjacentes a dois princípios da física quântica, desenvolvidos por Heisenberg e Schrödinger, vêm de encontro a presente pesquisa. O princípio da incerteza, desenvolvido por Heisenberg em 1927, tem dois enunciados: não se pode saber a velocidade da partícula e sua posição, ao mesmo tempo; e não se pode medir a energia da partícula e saber o momento exato da medição, ao mesmo tempo. Por causa disso, não se pode afirmar cientificamente que o vazio existe, já que tempo e espaço não podem ser medidos concomitantemente. Se, no momento da medição da energia no ambiente de vácuo uma partícula escapa, não se pode saber por causa do segundo enunciado do princípio de Heisenberg. Ao retirar a equação da física destes dois enunciados, o que sobressai é o pensamento de que o vazio não existe e o que você observa, muda no momento mesmo em que você olha para ele. Outra forma de expressar esse incômodo do princípio da incerteza é que para que ver algo, é preciso iluminá-lo. Mas a luz transforma e faz mover. Logo, temos apenas uma especulação parcial e incompleta do que vemos. Como os escravos presos na caverna ${ }^{2}$, a realidade para eles era o que thes era 
possível ver: a projeção das sombras do que passava em um muro, na escuridão do interior da caverna, iluminada apenas por uma fogueira. O mito da Caverna é uma metáfora do efeito do conhecimento: quanto mais você sabe, mais da realidade você pode ver. Poder ver, mais do que ser iluminado, é poder se dar conta dos muitos pontos de vista. Porque ver já não é o suficiente, contemporaneamente, o ponto de vista é o assunto.

E por que há uma preocupação com o modo como as coisas aparecem para nós? Há uma incredulidade original? Por que a luz é a metáfora do conhecimento? Esta pergunta Jacques Derrida se faz no livro Memórias de Cego - o autorretrato e outras ruínas, no qual diz que o ponto de vista é o seu tema e fala da experiência da cegueira ou da cegueira como alteridade do ver. Isso será visto mais adiante.

O outro princípio é o do gato de Schrödinger, desenvolvido pelo físico austríaco em 1935, para falar das superposições quânticas, isto é, a combinação de todos os possíveis estados do sistema como, por exemplo, as posições possíveis de uma partícula subatômica. O experimento mental do Gato de Schrödinger consiste em um gato preso dentro de uma caixa opaca, junto a um frasco de veneno e um contador Geiger ligados por relés, além de um martelo. O contador Geiger será acionado ou não. Se for, transmitirá movimento através dos relés; o martelo baterá no frasco de veneno, quebrando-o e o gato morrerá. Mas se o contador não acionar o martelo não quebrará o frasco e o gato permanecerá vivo. A experiência tem um tempo para acontecer e somente depois desse tempo é que se pode abrir a caixa. Só saberemos se o gato está vivo ou morto se abrirmos a caixa, mas se isso for feito, alteraremos a possibilidade do gato estar vivo ou morto. O estado do gato durante o tempo da experiência não importa. O que conta é a possibilidade dele estar vivo e morto porque se não pudermos identificá-lo, diremos que este corpo está em todos os estados. Não poderíamos inferir, por exemplo, que o gato não está em estado nenhum, já que foi colocado dentro da caixa e sabemos que ele está lá.

O corpo na caixa só tem importância a partir do momento em que se pode vê-lo. É preciso estar/olhar de frente, percorrer o todo, e ainda assim cada experiência de quem vê será sempre diferente, diversa da outra. Desse modo, posso considerar a experiência artística contemporânea inalcançável na sua inteireza, isto é, a experiência do ver é, ao mesmo tempo, experiência de cegueira. Ou posso considerá-la uma experiência de preenchimento dos vazios por analogia, já que é sempre incompleta. Ou ainda considerar como um preenchimento rizomático: 
a experiência do ver como uma cadeia incompleta, mas infinita. A fragilidade do ver está na precariedade da própria visibilidade.

A experiência, nesse sentido, sobretudo a experiência artística também se dá por analogia. É impossível vê-la ou experimentá-la na sua totalidade. Ela se dá por vórtices de analogias diferentes para cada um, porque depende das biografias, das formações. Como se experimentar fosse fazer uma espécie de anamnese. Para o médico, fazer a anamnese é fazer o histórico da doença que vai desde os sintomas iniciais até o momento da observação clínica, baseado no relato do paciente. Nesse sentido, anamnese é lembrança, rememoração, e, portanto, necessariamente incompleta e especulativa.

Jean-François Lyotard fala da experiência artística ou da experimentação artística como uma anamnese do visível. Mas aqui não tem o sentido de rememoração, ou de reelaboração de dados. É anamnese, na medida em que submete a visão ou o visível a um processo de reelaboração de seus pressupostos. Dessa forma, o filósofo propõe outro modelo de relação do sujeito com a obra de arte e de noção de obra de arte.

Todavia, antes de prosseguir com a noção de anamnese do visível, é preciso entender a noção de Lyotard de obra de arte. De acordo com o filósofo, ela é avessa à interpretação, isto é, não é da ordem do Logos, ela não quer significar. Ele vai além: considera a obra de arte um desmentido face à própria relação de interpretação, na medida da irredutibilidade da experiência estética, ou do figural a um sentido lógico-verbal.

O conceito de figural, de Lyotard, é a designação possível para as representações artísticas: é o visível, enquanto manifestação espacial e visual, e inapropriável por um discurso, mediante interpretação. Como se o visível tivesse uma espessura e opacidade que colocasse em questão o próprio discurso, isto é, a condição do discurso sobre o figural e a resistência desse último à significação linguística.

Mas se o figural é avesso à interpretação, ou, no mínimo, avesso à redução de seu significado a um sentido lógico-verbal, a única maneira de encará-lo, senti-lo, percebê-lo é pela desconstrução, na medida em que ele questiona a própria possibilidade de interpretação. A condição do visível aí é sua não visibilidade, aquilo que opõe resistência à significação. O figural é atravessado pela impossibilidade de ter o discurso linguístico como mediação neutra da significação, isto é, é a linguagem que resiste à significação. 
É preciso ter em conta, outrossim, que Lyotard não privilegia a visão: a visão ou o visível são entendidos como uma dimensão entre outras. Além disso, não é possível tomar o visível como uma realidade inquestionável. A realidade é o pressuposto. E, se é assim, expor é dar a examinar o pressuposto, é suspender a realidade, na medida em que o exposto jamais se revela completo, obra única; o exposto é, ele mesmo, o pressuposto da exposição.

Nesse sentido, seguindo o raciocínio de Lyotard, ver uma exposição pressupõe certo afastamento, uma distância que é inerente à própria condição de reflexão. Assim, na condição de exposição, na condição de apresentação de pressupostos inexponíveis daquela realidade, ver a obra, a exposição, é desconstruí-la, é sujeitar o espectador aos pressupostos que subjazem a ela.

Para Derrida, a ideia da distância é a ideia do entre; não é o que está longe, exatamente, mas é um lugar esquisito, que é abertura, clareira, rasgo "que se apresenta à vista com teimosia: a presença, e, por conseguinte, o conteúdo, a coisa mesma, o sentido, a verdade - a menos que não seja já o abismo deflorado em todo este desvelamento da diferença." (DERRIDA, 2012, p. 07) Isto é, a distância é o jogo mesmo de desvelamento, que sempre escapa. O movimento do desvelamento é a produção de outro véu, porque o desvelamento provoca véus: o desvelamento é a experiência mesma da distância, é mostrar a distância da distância. "É necessária a distância (que é necessária); deve-se manter a distância (Distanz!). Isto que nos falta, isto que nos falta fazer, e isto que se assemelha também a um conselho de homem para homem: para seduzir e não para deixar-se seduzir." (DERRIDA, 2012, p. 12).

O processo de experimentação, ou o trabalho de arte, implica num trabalho de imaginação criadora por parte do expectante. Cada um vai experimentar o que a experiência oferece, na sua possibilidade e na sua diferença.

Mas como ver contemporaneamente? O que é o ver na contemporaneidade? O que é ser contemporâneo? Giorgio Agamben, no ensaio "O que é o Contemporâneo?" (AGAMBEN, 2009, p. 65-66), baseado em Nietzsche, defende que estamos presos a um entendimento do tempo como um tempo histórico, que segue uma linha evolutiva, isto é, pensa o contemporâneo dentro de um tempo cronológico, como se fosse um devir histórico. Assim, contemporâneo seria o deslocado, o que tem certa inatualidade, o que está numa dissociação em relação 
ao tempo, mas simultânea: uma discronia. E justamente por causa desse deslocamento, alguns mais do que outros, podem perceber e apreender o seu tempo. A contemporaneidade, portanto, seria uma relação com o tempo, mas com o tempo histórico. O filósofo diz que o artista contemporâneo deve manter o olhar no seu tempo, para perceber não as luzes, mas o escuro. Isto é, é preciso permitir-se certa cegueira - o que não quer dizer uma passividade ou uma impossibilidade absoluta de ver - para poder ver esse escuro especial, que é inseparável das luzes. O contemporâneo percebe o escuro do seu tempo para interpelá-lo, no sentido de perceber aí uma luz que jamais nos alcançará, mas que se dirige a nós. Porque, no momento mesmo em que o escuro torna-se luz, ele já não é mais contemporâneo.

Porém, se pensarmos num tempo mais da ordem do kairos do que do chronos? Ainda no mesmo ensaio, o autor fala do contemporâneo como uma fratura nesse tempo linear, como um descontínuo, um intervalo, como se o escuro fosse, em todos os tempos, aquilo que jamais conseguimos enxergar, isto é, o contemporâneo como um eterno retorno, como um permanente voltar-se para um presente onde jamais estivemos. Falar disso não é dizer que o contemporâneo carrega nele a sua arkhé, ou seja, ao mesmo tempo em que ele está distante, ele mantém uma proximidade de certa origem? Mas há uma origem original, há um arcaísmo primeiro, uma fonte?

Não, não se pode afirmar uma origem. A origem é sempre devir, assim como o contemporâneo:

o contemporâneo (...) é aquele que dividindo e interpolando o tempo está à altura de transformá-lo e de colocá-lo em relação com os outros tempos, de nele ler de modo inédito a história, de "citá-la" segundo uma necessidade que não provém de maneira nenhuma de seu arbítrio, mas de uma exigência à qual ele não pode responder. (AGAMBEN, 2009, p. 72)

Se a condição contemporânea é assim, fazer e ver arte contemporânea estão na mesma ordem. Todavia o ver não necessariamente é condição do fazer. Tanto faz se o artista está na experiência do fazer, ou se ele é, naquele momento observador e paciente da experiência artística. A experiência é da mesma natureza, é sempre criadora, na medida em que a obra, a experiência artística, apresenta-se não para ser apreendida enquanto um todo articulado de sentido, mas como uma proposta de visão, de questionamento de seus pressupostos, de sua identidade enquanto obra. Em entrevista a Glória Ferreira (FERREIRA, 2011, p.45), o artista 
italiano Luciano Fabro dizia que o artista fazia coisas não "em reação", mas em relação, porque naquele momento certas coisas Ihe são necessárias. Essa relação pode ser entendida como a desconstrução permanente que é a relação obra/experiência artística versus expectante, de questionamento de seus pressupostos, a partir dos vórtices de analogias/genealogias. $\mathrm{E}$ tanto vale para a experiência do fazer artístico como para o experienciar a obra de arte, seja ela objetual ou experiência, vivência.

Nesse sentido, ainda é possível falar do visível? O visível é apropriável pelo discurso? (Ou, para voltar à questão da ação clínica, é possível falar, construir um discurso sobre o visível?) Para Lyotard, a manifestação espacial e visual é irredutível à significação linguística (GOMES, 2002. p. 129-161). No entanto, essa indizibilidade, essa resistência ao discurso é que vai converter o seu sentido em significação linguística. Essa opacidade e espessura do visível é que serão a condição do discurso. Derrida chamaria esse visível resistente ao discurso, ou à escrita, de escritura, na medida em que eles são entendidos justamente por isso, pela sua irredutibilidade ao signo e à significação e, por isso mesmo, sujeitos a um processo de desconstrução. E a desconstrução é interminável: inversão e deslocamento; a inversão abre espaço para a alteridade indizível e o deslocamento sempre solidifica outras oposições, permanentemente. A escritura é, então, a falha da fala. Porque sua tarefa é liberar sentido, significante que gera significante e que não está mais preso ao significado. Isto é, o visível só é ou só há, pela contaminação do não visível, que coloca permanentemente em questão o visível. Ver pressupondo os não ditos, com os lapsos, os brancos.

E o gato? Se é assim, a quem importa ver o gato, ou abrir a caixa? Ou ainda, dependendo do ponto de vista, desejar ser o gato? O artista é aquele que está em todas essas experiências e que propõe ao observador que as viva, da mesma maneira, de acordo com suas diferenças. Daí a ideia do expectante, daí a ideia de uma observação sempre criativa da obra ou da experiência. O artista abre fendas no mundo, questionando-o e questionando-as, sem jamais querer preenchê-las ou dar conta delas. Ele as olha e experimenta. Quer ter todos os pontos de vista possíveis, quer observar a caixa sem abri-la; não quer abrir a caixa, pois pouco importa o estado do gato; quer abrir a caixa e ver o gato; e quer ser o gato. Nesse sentido, o artista pode se apoiar na filosofia ou em outras disciplinas, não para explicar as fendas, mas para descobri-las e explorá-las, ou para repercutir teoricamente, na ordem da palavra, do discurso, o buraco que se abriu. Quem quiser que tente tampá-los. 
Para ver, é preciso estar de frente - seja lá como for esse ver, com o tato, com o olfato, com a audição, etc. Por ser preciso estar de frente para ver, está pressuposta alguma distância entre o que vê e o que é visto - o distanciamento é condição da visibilidade. No texto Pensar em não ver, Derrida lembra que os olhos humanos veem de frente, veem o horizonte, ou veem na horizontal. O ver de frente antecipa a coisa. No entanto, a coisa mesma sempre escapa, ver/ estar com a coisa na sua totalidade é impossível. Nesse sentido, lidamos com a metaforicidade do "real", uma espécie de "como se" da coisa, da origem. Nietzsche dizia que a relação do homem com o mundo é interditada desde o início. Então ele cria uma relação do homem com o mundo, como se o homem tecesse uma rede, uma colmeia sobre o mundo, como se houvesse véus entre o pensamento e a verdade (no nosso caso, entre o pensamento e a coisa, o objeto ou a experiência artística), de modo que ver fosse como um jogo de descobrimento de véus, onde há sempre um outro véu e mais outro, de maneira a manter esse distanciamento, esse afastamento como possibilidade de visualidade. Ou, dizendo de outra maneira, a metaforicidade ${ }^{3}$ do "real" como condição de visualidade.

Voltando a Derrida, a obra de arte, ou a experiência artística, não comparece, nem se presentifica; ela é evento, é da ordem do acontecimento. E o acontecimento não se antecipa, não se apresenta no horizonte, ele vem da vertical, ou pelos lados, por trás, onde os olhos não têm alcance antecipatório. Para o acontecimento, o ponto de vista só vem depois, que é o ponto do desvelamento.

Não se foge do velamento. Desconstruir o que se vê (ou toca, ou cheira, ou ouve etc.), esse questionamento permanente, é um movimento pulsional, desejante, como uma perversão. $\mathrm{O}$ fazer/observar ou o expectar artístico não foge desse movimento constante, ou desse jogo. Está sempre em relação; se é assim, há negociação. O expectar artístico não está isolado do mundo, ele é produzido no mundo, no ato e só é considerado arte, se se inscrever, negociar sua condição artística a cada momento. É um processo, que implica muitas ações, atos e atores. No momento em que acontece, não é imediatamente arte. Chega como evento numa cadeia de acontecimentos e sua condição artística vai ser determinada pelas negociações, recepção e ressonâncias. Essa cadeia está numa espécie de rede que seria o mundo, ou o que há, e as inscrições nessa rede seriam propriamente o tecer a rede, criar novos nós, que são os pontos de vista, criar ritmos diferentes de criação desses novos nós. Ora, isso é política e não se faz política sem analogias ou remetimentos ou agenciamentos. 
De volta ao livro Memórias de Cego, O autorretrato e outras ruínas. Para ver o que está na obscuridade, seria preciso mais que o sentido da visão, seria necessário o tato. Tatear o escuro para enxergar ali o que se dá a ver. Nesse livro Derrida fala da cegueira do artista desenhador. No momento mesmo de desenhar, ainda que o modelo esteja bem à sua frente, ele tem que tirar os olhos do seu referente e desenhar de memória. O momento mesmo do desenho é cego e é ruína na origem. Como se o desenhador pudesse ter olhos na ponta dos dedos, quase tateando a memória para colocar o traço no papel. Esse momento de cegueira não é vivido somente pelo desenhador, mas por quase todo artista. No final do livro, o filósofo conclui que o olho, no fundo, não está destinado a ver. O próprio do olho, ou a essência do olho é a lágrima, porque é no momento do velamento, do enceguecimento pela água, que se revela a verdade do olho, a cegueira reveladora:

\begin{abstract}
Apenas ele sabe ver isso [voirça], o homem, que as lágrimas são a essência do olho - e não a visão. A essência do olho é o próprio do homem. Contrariamente ao que se crê saber, o melhor ponto de vista (o ponto de vista [point de vue] terá sido nosso tema) é um ponto de fonte [point de source] e um ponto de água [point d'eau] - vem a ser as lágrimas. A cegueira que abre o olho não é a que entenebrece a vista. A cegueira reveladora, a cegueira apocalíptica, a que revela a própria verdade dos olhos, seria o olhar velado de lágrimas. (DERRIDA, 2010, p. 130)
\end{abstract}

Mas essa cegueira da qual fala Derrida não é reveladora, somente porque a lágrima vela a vista. Ela é reveladora porque, no momento do desenho, quando o lápis encosta no papel e é só memória, é ruína. E é ruína cheia de espectralidade, carregada de fantasmas, é a visibilidade possível e porque, plena de espectros, é retórica.

Inelutável modalidade do visível: pelo menos isso se não mais, pensado através dos meus olhos. (...) Limites do diáfano. Mas êle acrescenta: nos corpos. Então êle se compenetrava dêles, corpos antes deles coloridos. Como? Batendo em sua cachola contra eles, com os diabos. Devagar. Calvo êle era e milionário, maestro di color chesanno. Limite do diáfano em. Por quê em? Diáfano, adiáfano. Se se pode pôr os cinco dedos através, é porque é uma grade, se não uma porta. Fecha os olhos e vê. (JOYCE, 1066, p. 41-42)

Artigo recebido em julho de 2015 e aprovado em agosto de 2015. 


\section{Notas}

$1 \mathrm{Na}$ cidade de Bayreuth, Wagner ergueu um teatro, cuja arquitetura e construção acompanhou passo a passo, especialmente para o ciclo O Anel dos Nibelungos, espetáculo que ele criou como o exemplo do que seria, a seu ver, a obra de arte total. A ideia era de que a opera pudesse elevar esteticamente o homem, com a união de todas as artes num só espetáculo. Para esse projeto, Wagner colocou a orquestra no fosso, para a música ser ouvida, sem que os músicos fossem vistos. Até hoje o teatro existe, e é onde acontece anualmente o Festival de Bayreuth.

2 No livro 7 da República de Platão, diálogo entre Sócrates e Gláucio.

3 A partir de sua relação com o mundo Nietzsche cria a ideia de metaforicidade, que não é a reabilitação da metáfora, e que supõe o afastar-se, o deslocar-se, o desviar-se, no sentido de fazer justiça ao movimento de escapar, ao jogo dos véus.

\section{Referências Bibliográficas}

AGAMBEM, Giorgio. O que é o contemporâneo? e outros ensaios. Tradução Vinícius NicastroHonesko. Chapecó: Argos, 2009.

DERRIDA, Jacques. Positions. Paris: Les Éditionsde Minuit, 1972

Éperons: les styles de Nietzsche. Paris: Flammarion, 1978.

Memórias de cego, O auto-retrato e outras ruínas. Tradução Fernanda Bernardo. Lisboa: Fundação Calouste

Gulbenkian, 2010.

FERREIRA, Glória. Entrefalas / [entrevistas realizadas por] Glória Ferreira. Porto Alegre: Zouk, 2011.

FOUCAULT, Michel. O Nascimento da clínica. Tradução: Roberto Machado. Rio de Janeiro: Forense Universitária: 1998.

Surveiller et punir: naissance de la prison. Paris, Gallimard, 1975.

Estratégia, poder-saber. Tradução: Vera Lúcia Avellar Ribeiro. Coleção Ditos \& Escritos IV. Rio de Janeiro: Forense

Universitária, 2006.

FLUSSER, Vilém. Filosofia da caixa preta: ensaios para uma futura filosofia da fotografia. São Paulo: Annablume, 2011.

JOYCE, James. Ulisses. Tradução Antônio Houaiss. Rio de Janeiro: Civilização Brasileira, 1966.

LYOTARD, Jean-François. Discours, figure. Paris: Klincksieck, 2002.

. A condição pós-moderna. Tradução Ricardo Corrêa Barbosa. Rio de Janeiro: José Olympio, 2011.

Peregrinações. Tradução Marina Appenzeller. São Paulo: Estação Liberdade, 2000.

MILLINGTON, Barry (org.) Wagner: um compêndio. Tradução Luiz Sampaio e Eduardo Francisco Alves. Rio de Janeiro: Jorge Zahar Ed., 1995. 
PLATÃO. A República. Tradução Maria Helena da Rocha Pereira. Lisboa: Fundação CalousteGulbenkian, 1949.

VALÉRY, Paul. A alma e a dança e outros diálogos. Tradução Marcelo Coelho. Rio de Janeiro: Imago, 1996.

\section{Periódicos}

Revista Filosófica de Coimbra, n. 21, 2002.

\section{Sites consultados}

http://www.cap.eca.usp.br/ars4.htm 